\title{
Monitoring of cerebral blood flow and metabolism bedside in patients with subarachnoid hemorrhage - a Xenon-CT and microdialysis study
}

\section{Elham Rostami ${ }^{1}$ *, Henrik Engquist ${ }^{2}$, Ulf Johnson ${ }^{1}$,Timothy Howells ${ }^{1}$, Elisabeth Ronne-Engström ${ }^{1}$, Pelle Nilsson ${ }^{1}$, Lars Hillered $^{1}$, Anders Lewén ${ }^{1}$ and Per Enblad ${ }^{1}$}

1 Section of Neurosurgery, Department of Neuroscience, Uppsala University, Uppsala, Sweden

${ }^{2}$ Anesthesiology and Intensive Care, Department of Surgical Sciences, Uppsala University, Uppsala, Sweden

Edited by:

Ibolja Cernak, University of Alberta,

Canada

Reviewed by:

Bruce G. Lyeth, University of California Davis, USA

Nikolaus Plesnila, Institute for Stroke and Dementia Research, Germany

*Correspondence:

Elham Rostami, Section of

Neurosurgery, Department of

Neuroscience, Uppsala University,

SE-751 85 Uppsala, Sweden

e-mail:elham.rostami@neuro.uu.se
Cerebral ischemia is the leading cause of morbidity and mortality following aneurysmal subarachnoid hemorrhage (SAH). Although $70 \%$ of the patients show angiographic vasospasm only $30 \%$ develop symptomatic vasospasm defined as delayed cerebral ischemia (DCI). Early detection and management of reversible ischemia is of critical importance in patients with SAH. Using a bedside Xenon enhanced computerized tomography (Xenon-CT) scanner makes it possible to measure quantitative regional Cerebral blood flow (CBF) bedside in the neurointensive care setting and intracerebral microdialysis (MD) is a method that offers the possibility to monitor the metabolic state of the brain continuously. Here, we present results from nine SAH patients with both MD monitoring and bedside Xenon-CT measurements. CBF measurements were performed within the first $72 \mathrm{~h}$ following bleeding. Six out of nine patients developed $\mathrm{DCl}$ at a later stage. Five out of six patients who developed DCl had initial global CBF below $26 \mathrm{ml} / 100 \mathrm{~g} / \mathrm{min}$ whereas one had $53 \mathrm{ml} / 100 \mathrm{~g} / \mathrm{min}$. The three patients who did not develop clinical vasospasm all had initial global CBF above $27 \mathrm{ml} / 100 \mathrm{~g} / \mathrm{min}$. High lactate/pyruvate (L/P) ratio was associated with lower CBF values in the area surrounding the catheter. Five out of nine patients had L/P ratio $\geq 25$ and four of these patients had $\mathrm{CBF} \leq 22 \mathrm{ml} / 100 \mathrm{~g} / \mathrm{min}$. These preliminary results suggest that patients with initially low global CBF on Xenon-CT may be more likely to develop DCl. Initially low global CBF was accompanied with metabolic disturbances determined by the MD. Most importantly, pathological findings on the Xenon-CT and MD could be observed before any clinical signs of $\mathrm{DCl}$. Combining bedside Xenon-CT and MD was found to be useful and feasible. Further studies are needed to evaluate if $\mathrm{DCl}$ can be detected before any other signs of $\mathrm{DCl}$ to prevent progress to infarction.

Keywords: cerebral blood flow, subarachnoid hemorrhage, neurointensive care, Xenon-CT, imaging, vasospasm, microdialysis

\section{INTRODUCTION}

Positron emission tomography (PET) studies have shown that subarachnoid hemorrhage (SAH) causes both global and focal hemodynamic and metabolic disturbances in the brain early after aneurysm rupture (1), which makes the brain vulnerability for secondary insults (2-4). Secondary ischemic brain injury may be caused by cerebral vasospasm and also by various other secondary insults, e.g., high intracranial pressure (ICP), hypotension, hypoxemia, and seizures. Microcirculatory dysfunction, microthrombosis, cortical spreading depression, inflammation, and disturbances in cerebral autoregulation are today considered to be important mechanisms for the development of secondary ischemia in SAH (3, 5). Vasospasm is defined as the narrowing of intracranial arteries. The clinical definition of vasospasm has often been based on the methods applied for diagnosis such as angiography, transcranial Doppler (TCD), symptomatology, and imaging (5). Using clinical definitions, cerebral vasospasm has shown to be the leading cause of morbidity and mortality following aneurysmal SAH (6). It is estimated that $70 \%$ of the patients develop vasospasm diagnosed by angiography $(7,8)$, while only $30-50 \%$ develop symptomatic vasospasm $(9,10)$. This discrepancy between angiographic findings and development of clinical signs is one of the reasons why the role of macrovascular narrowing has been questioned as the major mechanism for the development of ischemia. Current guidelines of the critical care management of patients with SAH recommend the use of the term delayed cerebral ischemia (DCI), defined as focal neurological impairment or decrease of Glasgow coma score, and/or radiological signs of ischemia/infarction (11).

Reduced cerebral blood flow (CBF) becomes symptomatic below the critical threshold for electrical/functional disturbances $(12,13)$. If sustained, it will lead to irreversible ischemia and finally infarction. Thus early detection of low CBF is of critical importance in patients with SAH.

Currently, the detection of vasospasm is routinely based on the repeated neurological examinations, TCD blood flow velocity measurements and angiography. When treating patients with 
severe SAH, it would be desirable to have more accurate methods for the measurements of regional and global CBF at the bedside in the neurointensive care (NIC) unit. A few centers have used a bedside Xenon enhanced computerized tomography (Xenon-CT) in the NIC setting, and their experiences indicate that this may be an attractive solution (14-16). XenonCT has been shown to be feasible and valuable in detecting early signs of vasospasm/low $\mathrm{CBF}$ and to predict development of infarction $(17,18)$. Hypoperfusion measured by Xenon-CT during the first $24 \mathrm{~h}$ following $\mathrm{SAH}$ has been shown to correlate with worse outcome (19). We have introduced a new protocol for the management of $\mathrm{SAH}$ patients at our department adding bedside Xenon-CT to current neuromonitoring in order to measure CBF. Here, we present our first results from nine patients suffering from severe $\mathrm{SAH}$ who were examined with Xenon-CT and simultaneously monitored by intracerebral microdialysis (MD).

\section{MATERIALS AND METHODS \\ STUDY POPULATION AND STUDY DESIGN}

Nine patients with aneurysmal SAH who were admitted to the Department of Neurosurgery, Uppsala University Hospital, between October 2012 and July 2013 were included in the study (Table 1). All but one of the nine patients were female. The average age was $56.2 \pm 13.2$.

Inclusion criteria were mechanically ventilated SAH patients with intraventricular catheter and MD monitoring who underwent Xenon-CT within $72 \mathrm{~h}$ of symptom onset. Patients with a pre-existing neurological deficit or a SAH resulting from trauma or arterio-venous malformation (AVM) were excluded. The SAH was verified by CT scanning and the aneurysm was visualized by a CT angiography or digital subtraction angiography. All patients included in the study were enrolled within $24 \mathrm{~h}$ from the onset of SAH. All patients underwent surgical clipping $(n=1)$ or endovascular coiling $(n=8)$ of the ruptured aneurysm within the first day except one patient who underwent endovascular coiling after 2 days.

\section{NEUROINTENSIVE CARE}

All SAH patients were managed according to a standardized protocol based on intensive physiological monitoring and aggressive therapy of any derangement to avoid or minimize secondary brain injury (4). All unconscious patients and patients with clinical and radiological signs of intracranial hypertension received a ventriculostomy. If ICP was above $20 \mathrm{mmHg}$, the drainage system was opened and cerebrospinal fluid drained against a pressure level of $15 \mathrm{mmHg}$. Hypotension was treated first with albumin $20 \%$ and crystalloid solutions and with Dobutamine if needed. The goal was to keep CPP above $60 \mathrm{mmHg}$. Identified aneurysms were treated early by endovascular coiling or surgical clipping. All patients received nimodipine (Nimotop ${ }^{\circledR}$, Bayer AB, Solna, Sweden). The patients were diagnosed to have DCI when delayed ischemic neurological deterioration/deficits occurred that could not be explained by other reasons, i.e., clot, hydrocephalus, or infection. DCI was treated with hypertensive, hypervolemic, and hemodilution therapy (triple- $\mathrm{H}$ therapy) by the administration of Dextran 40 solutions $500 \mathrm{ml} /$ day (Rheomacrodex ${ }^{\circledR}, 100 \mathrm{mg} / \mathrm{ml}$,
Table 1 | Patient demographics and clinical characteristics of nine SAH patients.

\begin{tabular}{lcccccccc}
\hline Patient & Sex & Age & DCI & $\begin{array}{c}\text { H\&H } \\
\text { CT- } \\
\text { Fisher }\end{array}$ & Treatment & $\begin{array}{l}\text { GCS-M } \\
\text { in }\end{array}$ & $\begin{array}{l}\text { GCS-M } \\
\text { out }\end{array}$ \\
\hline 1 & & & & & & & & \\
2 & F & 51 & No & 1 & 3 & Clipping & 6 & 6 \\
3 & F & 73 & Yes & 3 & $4 c$ & Coiling & 6 & 4 \\
4 & F & 64 & Yes & 3 & $4 c$ & Coiling & 6 & 6 \\
5 & F & 28 & No & 5 & $4 a$ & Coiling & 1 & 6 \\
6 & F & 56 & Yes & 4 & $4 a$ & Coiling & 5 & 6 \\
7 & F & 67 & No & 2 & $4 a$ & Coiling & 6 & 4 \\
8 & M & 54 & Yes & 4 & $4 a$ & Coiling & 4 & 6 \\
9 & F & 64 & Yes & 1 & $4 a$ & Coiling & 6 & 5 \\
& F & 49 & Yes & 2 & $4 a$ & Coiling & 6 & 6 \\
\hline
\end{tabular}

The Hunt \& Hess grade is based on the status at admission and CT-fishers grade is based on the initial CT. GCS-M, Glasgow coma scale motor response.

Meda AB, Solna, Sweden $)$ and Albumin $100 \mathrm{ml}, 2 \times(200 \mathrm{mg} / \mathrm{ml}$, Baxter Medical AB, Kista, Sweden).

\section{CBF MEASUREMENTS}

As a part of the new protocol at our department, Xenon-CT is performed bedside in the NIC unit on all patients with SAH within the first $72 \mathrm{~h}$ after admission. CBF measurements using Xenon-CT were performed bedside in our NIC unit according to the principles described by Yonas et al. (20-23). The Xenon gas is a radio opaque, highly lipid soluble, and capable of crossing the BBB. The Kety-Schmidt equation is applied to measure regional and global CBF (24). Stable Xenon at a concentration of $28 \%$ was administered to the patients breathing circuit for about $4 \mathrm{~min}$ using the Enhancer 3000 and computer software (Diversified Diagnostic Products Inc., Houston, USA). During the Xenon inhalation, CT scans were obtained by the CereTom ${ }^{\circledR}$ (Neurologica, Boston, USA). The Xenon delivery and the CT scans were synchronized by computer software and the resulting radiologic tissue enhancement of the Xenon wash-in enabled CBF $(\mathrm{ml} / 100 \mathrm{~g} / \mathrm{min})$ to be calculated and plotted as colored maps in scans at four different levels of the brain (eight scans per level, two baselines and six enhanced, with 10-mm spacing).

Mean blood flow in each of 20 evenly distributed cortical regions (ROIs) was calculated for each level (Figure 1). The global $\mathrm{CBF}$ is given as a mean of all four levels. The tip of the MD catheter was identified on the structural CT scans and a ROI was drawn manually for the corresponding area around the MD catheter on the CBF scans (Figure 1). The vascular territories were analyzed as following: anterior cerebral artery ROI 1-2 (right) and 19-20 (left), middle cerebral artery ROI 3-8 (right) and 13-18 (left), and posterior cerebral artery ROI 9-10 (right) and 11-12 (left). Territories with CT-defined hematoma or artifact were noted and excluded.

\section{CEREBRAL MICRODIALYSIS}

The cerebral MD technique in NIC has previously been extensively used and described $(25,26)$. The intracerebral MD catheter was placed in the right frontal lobe cortex through a separate burr hole, anterior to the ventricular drain. The anatomical location 
of the MD catheters was evaluated by CT scans. For intracerebral monitoring, we used 70 Brain Microdialysis Catheter (M Dialysis $A B$, Solna, Sweden) with a membrane length of $10 \mathrm{~mm}$ and a membrane cutoff of 20,000 Da was used for intracerebral MD. The catheters were perfused with artificial CSF $\left(\mathrm{Na}^{+}, 147 \mathrm{mM}\right.$; $\mathrm{Ca}^{2+}, 1.2 \mathrm{mM}$; $\mathrm{Mg}^{2+}, 0.85 \mathrm{mM} ; \mathrm{K}^{+}, 2.7 \mathrm{mM}$; and $\mathrm{Cl}^{-}, 152 \mathrm{mM}$ ). The perfusion rate was $0.3 \mu \mathrm{l} / \mathrm{min}$ using a microinjection pump (CMA-106, M Dialysis AB, Solna, Sweden). MD urea was monitored to validate catheter performance (27). The MD samples were collected on an hourly basis. MD samples for the 3-h period before and 3-h period after the Xenon-CT examination were used for analysis. Interstitial glucose, lactate, pyruvate, glutamate, glycerol,

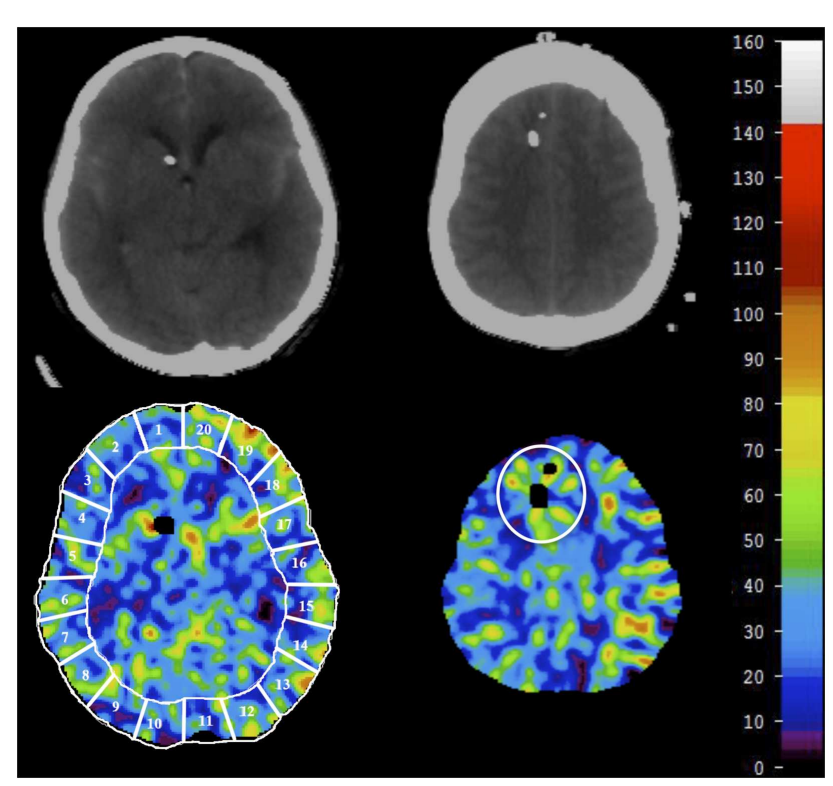

FIGURE 1 | At each level, CBF in 20 ROls was calculated and averaged for global CBF (lower left). The vascular territories were analyzed as follows: anterior cerebral artery ROI 1-2 (lower right) and 19-20 (lower left), middle cerebral artery ROI 3-8 (lower right) and 13-18 (lower left), and posterior cerebral artery ROI 9-10 (lower right) and 11-12 (lower left). For $\mathrm{CBF}$ around the microdialysis catheter, a ROI was manually drawn around the microdialysis catheter after localization on CT-scan (lower right). and urea were analyzed enzymatically using a CMA 600 analyzer (M Dialysis AB, Solna, Sweden). Quality control measurements using control samples for the CMA 600 microdialysis analyzer (M Dialysis AB, Solna, Sweden) were run daily.

\section{ETHICS}

The Uppsala University Regional Ethical Review Board for clinical research granted permission to undertake the study. Written informed consent was obtained from all patients or their proxy for study participation. The study was also approved by the local Radiation Safety Authority.

\section{RESULTS}

Demographics and clinical characteristics of the nine SAH patients studied are presented in Table 1. The Xenon-CT CBF measurements were performed within the first 3 days (mean 2.9 \pm 0.9 ) after bleeding and no complications were observed during the measurements. The physiological values during the CBF measurements are presented in Table 2. The ICP and CPP were within normal range $13.6 \pm 3.4 \mathrm{mmHg}$ and $77 \pm 10.2 \mathrm{mmHg}$, respectively and did not change compared to before and after CBF measurements (Figure 2). None of the patients were hyperventilated during the $\mathrm{CBF}$ measurements. The mean $\mathrm{pCO}_{2}$ was $5.1 \pm 0.3 \mathrm{kPa}$ and mean $\mathrm{pO}_{2}$ was $13.9 \pm 2.3 \mathrm{kPa}$. No significant changes could be observed in ICP, CPP, and MAP during and after CBF measurements compared with before. Six out of the nine patients developed DCI according to the applied definition (Table 1).

\section{GLOBAL CBF}

The mean global CBF was $35 \pm 20 \mathrm{ml} / 100 \mathrm{~g} / \mathrm{min}$ ( median $=25$, range 64) (Table 3). The correlations between global CBF and neurological grade, $\mathrm{CPP}, \mathrm{pCO}_{2}$, and amount of sedation, respectively, are shown in Figure 3. Five out of six patients who developed DCI had global CBF below $26 \mathrm{ml} / 100 \mathrm{~g} / \mathrm{min}$ whereas one had $53 \mathrm{ml} / 100 \mathrm{~g} / \mathrm{min}$ (Figure 4). Those three patients who did not develop DCI all had global CBF above $27 \mathrm{ml} / 100 \mathrm{~g} / \mathrm{min}$. Due to the low number of patients no statistics have been performed.

\section{REGIONAL CBF}

The results of CBF measurements in different vascular territories for each patient are presented in Table 3. The mean regional

Table 2 | Physiological parameters and neurological grade during the Xenon-CT CBF measurements are presented for each patient.

\begin{tabular}{|c|c|c|c|c|c|c|c|c|}
\hline Patient & ICP (mmHg) & MAP (mmHg) & CPP $(\mathrm{mmHg})$ & $\mathrm{FIO}_{2}(\%)$ & $\mathrm{pCO}_{2}(\mathrm{kPa})$ & $\mathrm{pO}_{2}(\mathrm{kPa})$ & Propofol (mg/kg/h) & GCS-M \\
\hline 1 & 15.8 & 104.9 & 89.1 & 30 & 5.1 & 13.6 & 5.9 & 5 \\
\hline 2 & 12.4 & 107.7 & 94.3 & 40 & 5.8 & 17.2 & 2.2 & 6 \\
\hline 4 & 15.3 & 84.8 & 71.9 & 30 & 5.4 & 17.4 & 5.2 & 6 \\
\hline 5 & 14.6 & 96.4 & 82.2 & 35 & 5.0 & 14.1 & 3.1 & 4 \\
\hline 8 & 18.9 & 87.2 & 68.4 & 40 & 5.0 & 9.9 & 3.3 & 5 \\
\hline 9 & 7.7 & 85.8 & 78.1 & 30 & 4.7 & 13.9 & 3.2 & 6 \\
\hline
\end{tabular}

ICP, intracranial pressure; MAP, mean arterial pressure; CPP, cerebral perfusion pressure; FIO 2 , fraction of inspired oxygen; GCS-M, Glasgow coma scale motor score. 
$\mathrm{CBF}$ was $37 \pm 22 \quad($ mean $\pm \mathrm{SD}) \mathrm{ml} / 100 \mathrm{~g} / \mathrm{min} \quad($ median $=30$, range $=68$ ) in the ACA territory, $34 \pm 17 \mathrm{ml} / 100 \mathrm{~g} / \mathrm{min}$ (median $=$ 26 , range $=80)$ in the PCA territory, $32 \pm 20 \mathrm{ml} / 100 \mathrm{~g} / \mathrm{min}$ $($ median $=29$, range $=60)$ in the MCA, and $28 \pm 14 \mathrm{ml} / 100 \mathrm{~g} / \mathrm{min}$ $($ median $=23$, range $=48)$ in the MD region (Table 3$)$. No obvious lateralization of low CBF in relation to the aneurysm location could be seen. There were individual differences in each patient in different vascular territories, e.g., in patient 2 there was a $50 \%$ decrease in the left posterior circulation compared to global $\mathrm{CBF}$ while there was an increase in the right side. Patient 5 showed a $24 \%$ decrease in CBF in the right anterior circulation while there was a $15 \%$ increase in the right posterior circulation. Four patients showed $>20 \%$ difference between the

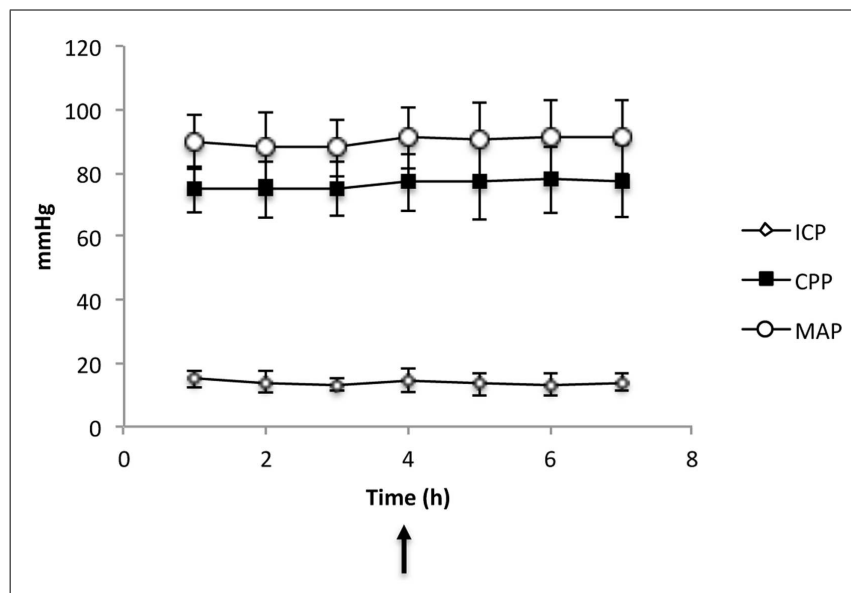

FIGURE 2 | Physiological parameters (CPP, cerebral perfusion pressure; MAP, mean arterial pressure) and ICP (Intracranial pressure) in all nine patients before and after Xenon-CT (indicated by the arrow). The values are given as mean \pm SD. two sides in the anterior circulation, one patient in the posterior circulation and three patients in the middle vascular territory (Table 3).

\section{MICRODIALYSIS AND CBF}

All patients had lower $\mathrm{CBF}$ in the region around the catheter $(28 \pm 14 \mathrm{ml} / 100 \mathrm{~g} / \mathrm{min})$ compared to global $\mathrm{CBF}$ $(35 \pm 20 \mathrm{ml} / 100 \mathrm{~g} / \mathrm{min})$ (Table 3$)$. High lactate/pyruvate (L/P) ratios tended to be correlated with lower CBF values in the area surrounding the catheter and there appeared to be a critical CBF threshold at around $20 \mathrm{ml} / 100 \mathrm{~g} / \mathrm{min}$ (Figure 5). Five out of nine patients also had $\mathrm{L} / \mathrm{P}$ ratio $\geq 25$ four of these patients had $\mathrm{CBF} \leq 22 \mathrm{ml} / 100 \mathrm{~g} / \mathrm{min}$. These four patients presented high glutamate levels. No correlation was evident between glucose and regional CBF (Figure 5). In patients 6 and 8, the glucose levels were $<1 \mathrm{mmol} / \mathrm{l}$ and these patients had $\mathrm{CBF} \leq 22 \mathrm{ml} / 100 \mathrm{~g} / \mathrm{min}$, high $\mathrm{L} / \mathrm{P}$ ratio, and high glutamate levels. In the patients who develop DCI, five had CBF $\leq 23 \mathrm{ml} / 100 \mathrm{~g} / \mathrm{min}$ in the region around the catheter. One with CBF $18 \mathrm{ml} / 100 \mathrm{~g} / \mathrm{min}$ presented with $\mathrm{L} / \mathrm{P}$ ratio of 77 and glutamate $66 \mu \mathrm{mol} / \mathrm{l}$. Patient 8 displayed the lowest $\mathrm{CBF}$ in the region around the catheter $10 \mathrm{ml} / 100 \mathrm{~g} / \mathrm{min}$ and had a L/P 48 and glutamate $28 \mu \mathrm{mol} / \mathrm{l}$. Patient 7 showed $\mathrm{CBF}$ of $46 \mathrm{ml} / 100 \mathrm{~g} / \mathrm{min}$ with low $\mathrm{L} / \mathrm{P}$ ratio of 16 and glutamate $6 \mu \mathrm{mol} / \mathrm{l}$.

\section{DISCUSSION}

In this pilot study including nine SAH patients, the first results of Xenon-CT CBF imaging bedside in combination with simultaneous monitoring of cerebral metabolism using MD are presented. We found the use of bedside Xenon-CT feasible and useful in assessing regional CBF in the NIC unit as reported by others (15, 28). No complications occurred during the CBF measurements and the physiological parameters remained within their normal ranges. A previous multicenter study reported the safety of this method with a very low risk of adverse events (14). Using bedside

Table 3 | Aneurysm location and CBF in different regions

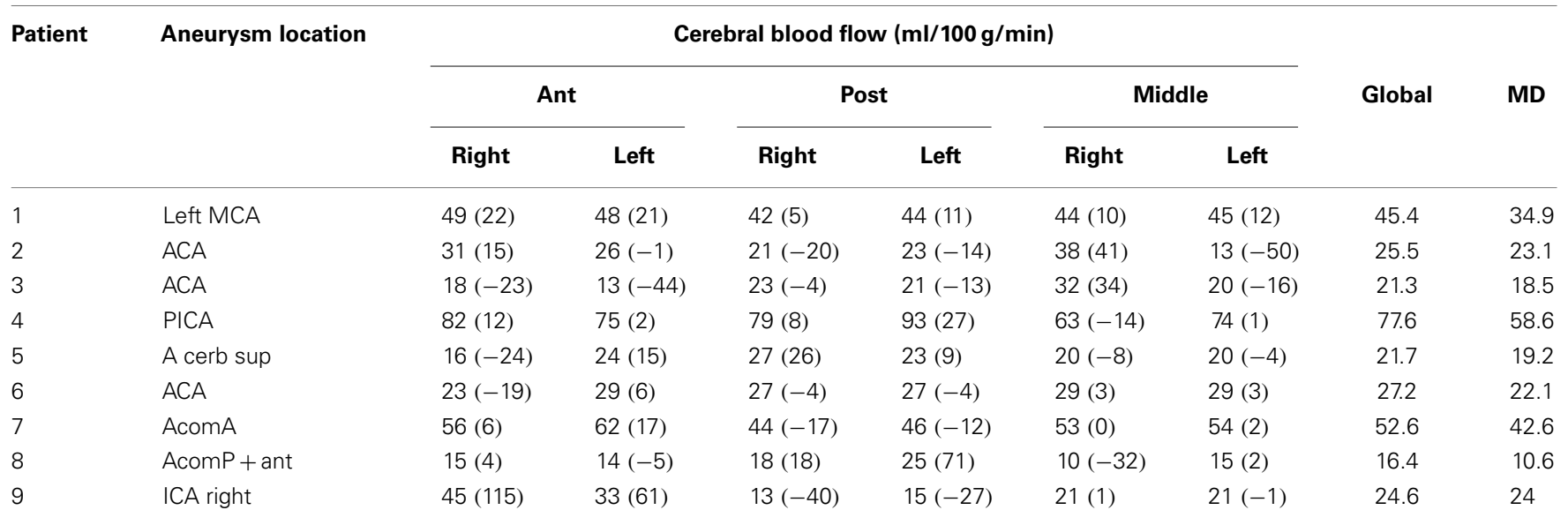

The changes in CBF between right and left side in different vascular regions compared to global CBF are presented in bracket (\%). $R$, right; $L$, left; $M C A$, middle cerebral artery; ACOA, anterior communicating artery; PCOA, posterior communicating artery; SCA, superior cerebellar artery; PICA, posterior inferior cerebellar artery; $M D$, microdialysis region. 

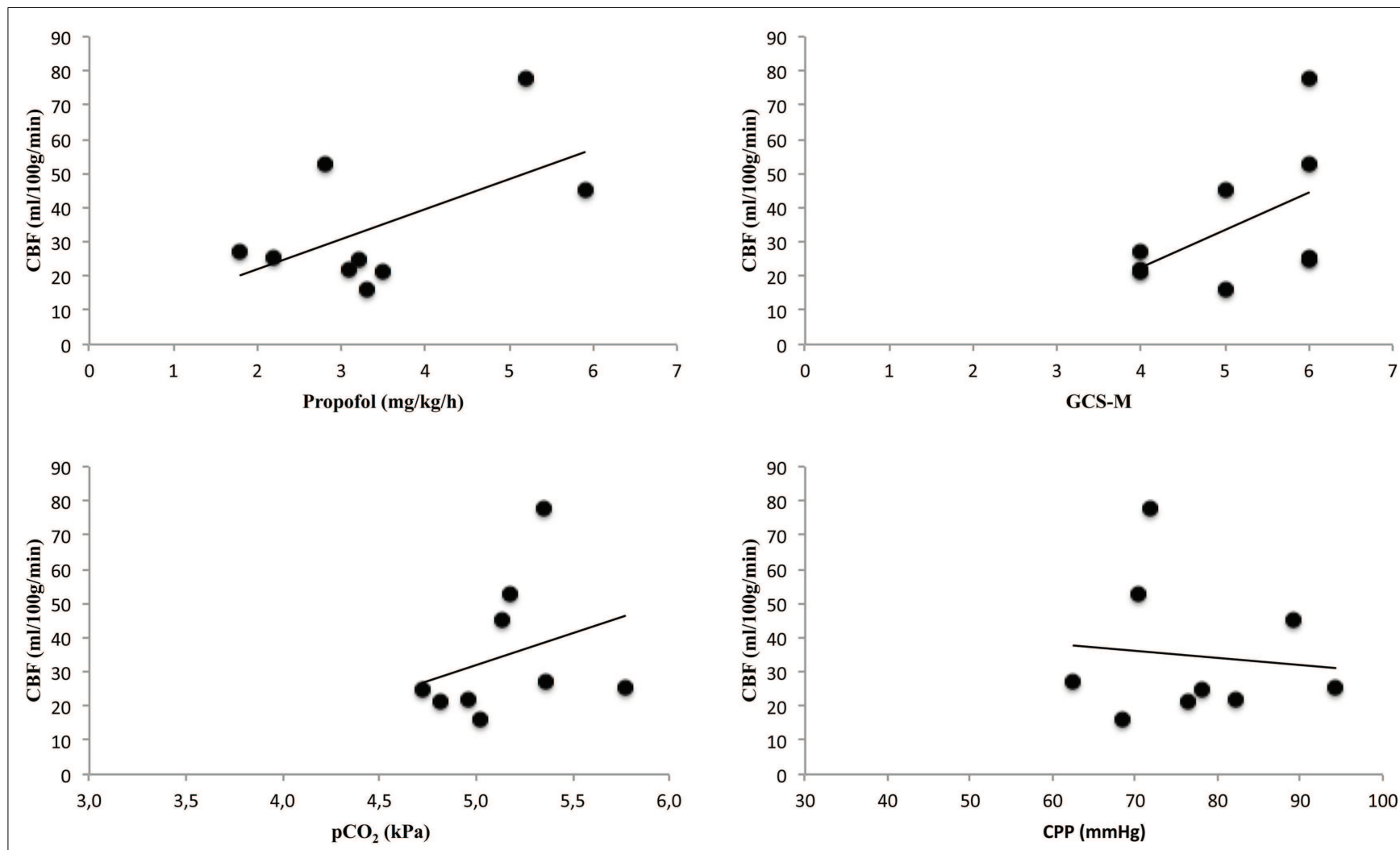

FIGURE 3 |The figure presents correlations between global cerebral blood flow (CBF) and the amount of sedation (Propofol), neurological grade (GCS-M, Glasgow coma scale motor score), $\mathrm{pCO}_{2}$, and cerebral perfusion pressure (CPP) during Xenon-CT measurements.

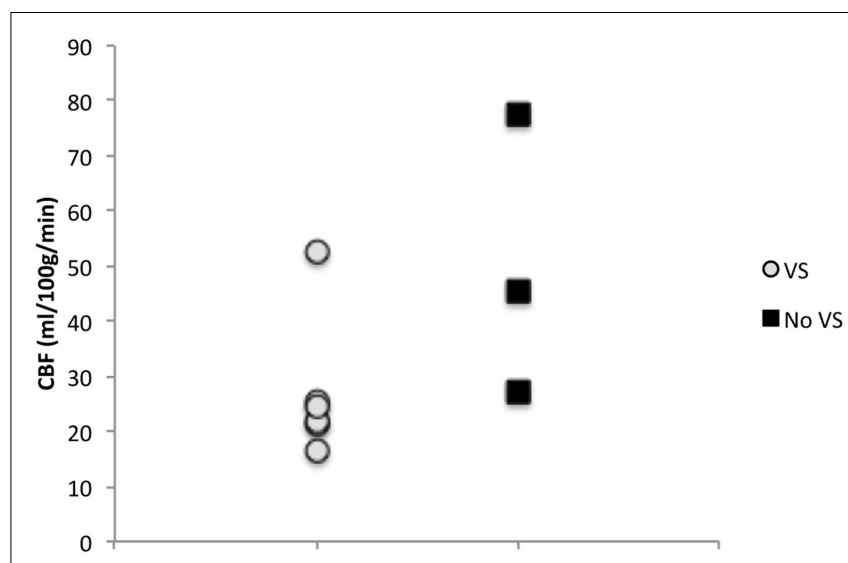

FIGURE 4 | Six out of nine patients developed DCI while three did not Patients that did not develop DCl tended to have higher initial CBF than patients who did develop $\mathrm{DCl}$.

Xenon-CT enables CBF measurements in unstable patients where transportation to the radiology department is associated with risks. The addition of bedside Xenon-CT CBF imaging to multimodality monitoring creates new possibilities for more accurate surveillance and guidance of treatment in NIC. More experience with the technique is needed in order to develop new algorithms for the NIC management.

The serious consequences of DCI following SAH are well known, but it is difficult to identify patients at risk. Our preliminary results suggest that patients with initial low global CBF, below $27 \mathrm{ml} / 100 \mathrm{~g} / \mathrm{min}$, on Xenon-CT may be more likely to develop DCI later. Previous studies using Xenon-CT have shown that cortical CBF in awake normal subjects is $52 \pm 10 \mathrm{ml} / 100 \mathrm{~g} / \mathrm{min}$ (21). In a study comparing comatose patients following head injury and normal subjects, a CBF threshold of $55.3 \mathrm{ml} / 100 \mathrm{~g} / \mathrm{min}$ was defined as hyperemia derived from normal CBF distribution (29). This study suggested CBF values $33.9-55.3 \mathrm{ml} / 100 \mathrm{~g} / \mathrm{min}$ as "relative hyperemia". CBF threshold values vary among different authors. However, studies in animal and humans have shown that $\mathrm{CBF}<6 \mathrm{ml} / 100 \mathrm{~g} / \mathrm{min}$ indicates severe ischemia and will lead to infarction, $\mathrm{CBF}>6$ and $<18 \mathrm{ml} / 100 \mathrm{~g} / \mathrm{min}$ are considered as reversible ischemia and $\mathrm{CBF}>18$ and $<33.9 \mathrm{ml} / 100 \mathrm{~g} / \mathrm{min}$ as reduced flow (29-31). In patients with clinical signs of DCI, low regional CBF levels were measured by Xenon-CT and regions with CBF below $15 \mathrm{ml} / 100 \mathrm{~g} / \mathrm{min}$ developed to infarction (18). Reduced global CBF ( $>18$ and $<33.9 \mathrm{ml} / 100 \mathrm{~g} / \mathrm{min}$ ) was seen in patients who developed DCI in the current study when Xenon-CT was performed within the first $72 \mathrm{~h}$. Currently, the triple- $\mathrm{H}$ therapy is initiated when clinical signs of vasospasm occur. However, if further studies confirm and demonstrate 


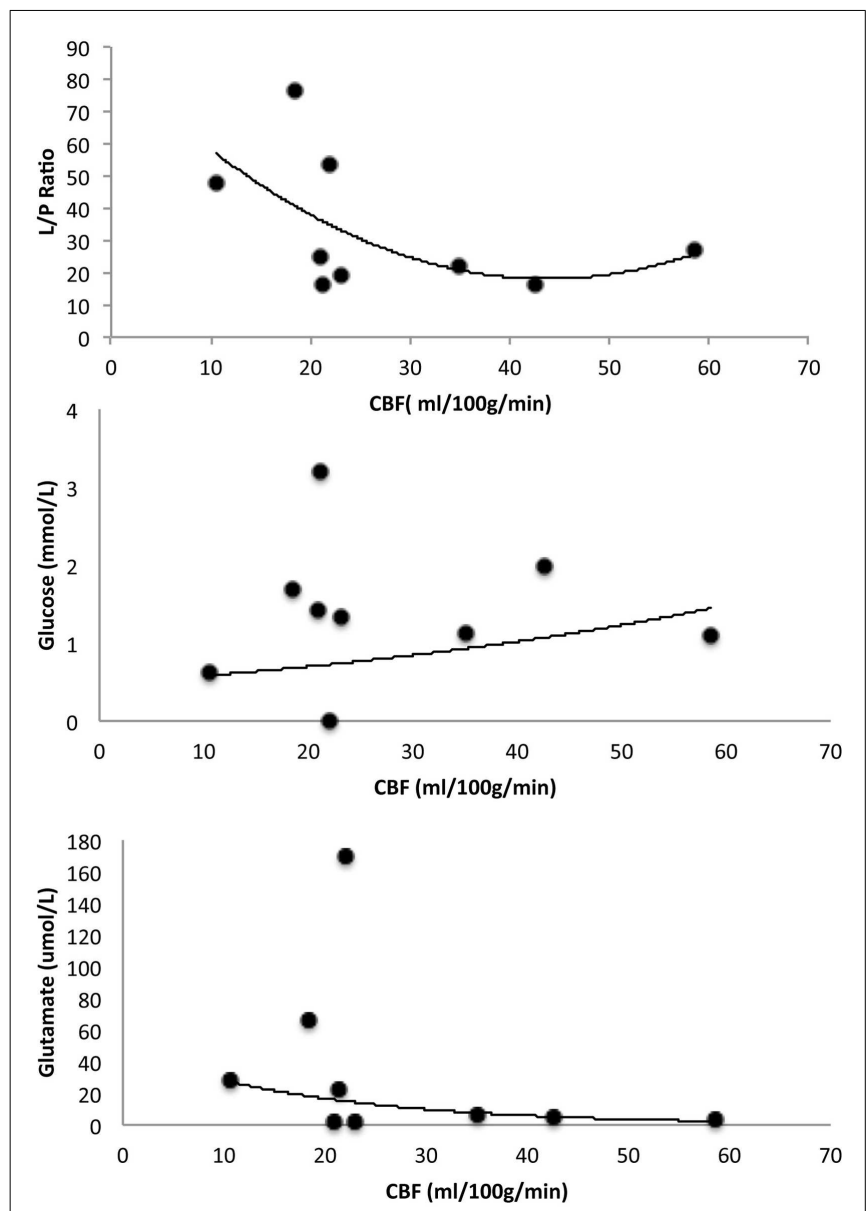

FIGURE 5 | Illustrates correlation between microdialyzate lactate/pyruvate (L/P) ratio and $C B F$, glucose and $C B F$, and glutamate and CBF. The CBF values represent the area surrounding the microdialysis catheter.

significant correlation between low initial CBF and development of vasospasm, prophylactic treatment could be initiated at an earlier stage in vulnerable patients at risk of irreversible cerebral damage. Furthermore, the effect of vasospasm therapy could also be evaluated.

The regional analysis of $\mathrm{CBF}$ showed decreased $\mathrm{CBF}$ in one or more of the vascular territories in most of the SAH patients. This finding is in accordance with an earlier PET study by Frykholm and coll. demonstrating that heterogeneous disturbances of regional CBF were present early after hemorrhage (1). The phenomenon may also be a warning of future risk of vasospasm and/or an indication of an increased vulnerability for various secondary insults (2). The underlying mechanisms for the observed reduced CBF early after $\mathrm{SAH}$ deserve further investigation. Interestingly, the suggested mechanisms may be disturbances in microcirculation and occurrence of microthrombosis that leads to reduce blood flow (32-35). This may also explain the findings of reduced CBF in the current study.

Using $\mathrm{MD}$, we observed high $\mathrm{L} / \mathrm{P}$ ratio and high glutamate levels when regional CBF was below $22 \mathrm{ml} / 100 \mathrm{~g} / \mathrm{min}$ in the MD region. Two previous smaller studies have combined MD with Xenon-CT in SAH patients. The first study included $16 \mathrm{SAH}$ patients that underwent Xenon-CT during day 3-10. No correlation could be found between L/P ratio and clinical status (36). Two patients in this study who developed infarction in the region of MD catheter had high glutamate levels. However, this study in contrast to the current did not correlate CBF with $\mathrm{L} / \mathrm{P}$ ratio and $\mathrm{CBF}$ measurements were later than $72 \mathrm{~h}$. In the second study, Al-Rawi et al. investigated the effect of hypertonic saline infusion on substrate delivery and metabolism by using $\mathrm{MD}$ and brain tissue oxygen sensor (37). A decrease of L/P ratio was observed in 9 out of $14 \mathrm{SAH}$ patients after hypertonic saline infusion and seven out of nine patients had an increase in CBF according to Xenon-CT. Previous studies have also combined MD with PET in order to assess both $\mathrm{CBF}$ and the metabolic state in SAH patients (38-40). Interestingly, the $\mathrm{L} / \mathrm{P}$ ratio has shown to be the most sensitive and specific MD parameter to indicate ischemia (40). Glutamate has been proposed as an early marker of threatening ischemia in SAH monitored by TCD (41). Using PET and MD glutamate showed high sensitivity for detecting a critically reduced regional CBF below $20 \mathrm{ml} / 100 \mathrm{~g} / \mathrm{min}$ (40). These studies are in accordance with findings in animal studies using PET and MD (42).

We did not observe an evident correlation between glucose and CBF, however, two patients with glucose levels $<1 \mathrm{mmol} / \mathrm{l}$ had $\mathrm{CBF} \leq 22 \mathrm{ml} / 100 \mathrm{~g} / \mathrm{min}$, high $\mathrm{L} / \mathrm{P}$ ratio and high glutamate levels. A low MD glucose level has been reported in $\mathrm{SAH}$ patients who develop infarct, and zero values of glucose were detected in patients with unfavorable outcome (43). Low regional brain glucose can depend on low CBF as well as hypo- and hypermetabolism.

\section{CONCLUSION}

The bedside Xenon-CT can be used safely for SAH patients in conjunction with MD monitoring of cerebral metabolism. The current pilot study includes few patients and therefore the results must be interpreted with caution. The results indicate that reduced $\mathrm{CBF}$ during the $72 \mathrm{~h}$ following symptom onset may be associated with increased risk of DCI and also with elevated $\mathrm{L} / \mathrm{P}$ ratio, which is a marker of disturbed energy metabolism.

\section{ACKNOWLEDGMENTS}

The authors would like to thank Johan Bäckander for excellent help with Xenon-CT measurements. This study was supported by the Swedish Research Council, the Uppsala University Hospital, and the Selander Foundation.

\section{REFERENCES}

1. Frykholm P, Andersson JL, Langstrom B, Persson L, Enblad P. Haemodynamic and metabolic disturbances in the acute stage of subarachnoid haemorrhage demonstrated by PET. Acta Neurol Scand (2004) 109:25-32. doi:10.1034/j.16000404.2003.00174.x

2. Enblad P, Persson L. Impact on clinical outcome of secondary brain insults during the neurointensive care of patients with subarachnoid haemorrhage: a pilot study. J Neurol Neurosurg Psychiatry (1997) 62:512-6. doi:10.1136/jnnp.62.5.512

3. Rowland MJ, Hadjipavlou G, Kelly M, Westbrook J, Pattinson KT. Delayed cerebral ischaemia after subarachnoid haemorrhage: looking beyond vasospasm. $\mathrm{Br}$ J Anaesth (2012) 109:315-29. doi:10.1093/bja/aes264 
4. Ryttlefors M, Howells T, Nilsson P, Ronne-Engstrom E, Enblad P. Secondary insults in subarachnoid hemorrhage: occurrence and impact on outcome and clinical deterioration. Neurosurgery (2007) 61:704-14; discussion 714-705. doi:10.1227/01.NEU.0000298898.38979.E3

5. Zheng Z, Sanchez-Porras R, Santos E, Unterberg AW, Sakowitz OW. Delayed cerebral ischemia after subarachnoid hemorrhage: from vascular spasm to cortical spreading depolarizations. Curr Neurovasc Res (2012) 9:310-9. doi:10.2174/ 156720212803530663

6. Schievink WI. Intracranial aneurysms. N Engl J Med (1997) 336:28-40. doi:10. 1056/NEJM199701023360106

7. Allcock JM, Drake CG. Ruptured intracranial aneurysms - the role of arterial spasm. J Neurosurg (1965) 22:21-9. doi:10.3171/jns.1965.22.1.0021

8. Biller J, Godersky JC, Adams HP Jr. Management of aneurysmal subarachnoid hemorrhage. Stroke (1988) 19:1300-5. doi:10.1161/01.STR.19.10.1300

9. Qureshi AI, Sung GY, Razumovsky AY, Lane K, Straw RN, Ulatowski JA. Early identification of patients at risk for symptomatic vasospasm after aneurysmal subarachnoid hemorrhage. Crit Care Med (2000) 28:984-90. doi:10.1097/ 00003246-200003000-00035

10. Solenski NJ, Haley EC Jr, Kassell NF, Kongable G, Germanson T, Truskowski L, et al. Medical complications of aneurysmal subarachnoid hemorrhage: a report of the multicenter, cooperative aneurysm study. Participants of the Multicenter Cooperative Aneurysm Study. Crit Care Med (1995) 23:1007-17. doi:10.1097/00003246-199506000-00004

11. Diringer MN, Bleck TP, Claude Hemphill J III, Menon D, Shutter L, Vespa $\mathrm{P}$, et al. Critical care management of patients following aneurysmal subarachnoid hemorrhage: recommendations from the Neurocritical Care Society's Multidisciplinary Consensus Conference. Neurocrit Care (2011) 15:211-40. doi:10.1007/s12028-011-9605-9

12. Astrup J, Siesjo BK, Symon L. Thresholds in cerebral ischemia - the ischemic penumbra. Stroke (1981) 12:723-5. doi:10.1161/01.STR.12.6.723

13. Astrup J, Symon L, Branston NM, Lassen NA. Cortical evoked potential and extracellular K+ and H+ at critical levels of brain ischemia. Stroke (1977) 8:51-7. doi:10.1161/01.STR.8.1.51

14. Carlson AP, Brown AM, Zager E, Uchino K, Marks MP, Robertson C, et al. Xenon-enhanced cerebral blood flow at $28 \%$ xenon provides uniquely safe access to quantitative, clinically useful cerebral blood flow information: a multicenter study. AJNR Am J Neuroradiol (2011) 32:1315-20. doi:10.3174/ajnr. A2522

15. Hillman J, Sturnegk P, Yonas H, Heron J, Sandborg M, Gunnarsson T, et al. Bedside monitoring of CBF with xenon-CT and a mobile scanner: a novel method in neurointensive care. Br J Neurosurg (2005) 19:395-401. doi:10.1080/ 02688690500389898

16. Yonas H, Wolfson SK Jr., Gur D, Latchaw RE, Good WF, Leanza R, et al. Clinical experience with the use of xenon-enhanced CT blood flow mapping in cerebral vascular disease. Stroke (1984) 15:443-50. doi:10.1161/01.STR.15.3.443

17. Sturnegk P, Mellergard P, Yonas H, Theodorsson A, Hillman J. Potential use of quantitative bedside CBF monitoring (Xe-CT) for decision making in neurosurgical intensive care. Br J Neurosurg (2007) 21:332-9. doi:10.1080/ 02688690701411574

18. Yonas H, Sekhar L, Johnson DW, Gur D. Determination of irreversible ischemia by xenon-enhanced computed tomographic monitoring of cerebral blood flow in patients with symptomatic vasospasm. Neurosurgery (1989) 24:368-72. doi:10.1227/00006123-198903000-00010

19. Schubert GA, Seiz M, Hegewald AA, Manville J, Thome C. Acute hypoperfusion immediately after subarachnoid hemorrhage: a xenon contrast-enhanced CT study. J Neurotrauma (2009) 26:2225-31. doi:10.1089/neu.2009.0924

20. Meyer JS, Shinohara T, Imai A, Kobari M, Sakai F, Hata T, et al. Imaging local cerebral blood flow by Xenon-enhanced computed tomography - technical optimization procedures. Neuroradiology (1988) 30:283-92. doi:10.1007/ BF00328177

21. Yonas H, Darby JM, Marks EC, Durham SR, Maxwell C. CBF measured by XeCT: approach to analysis and normal values. J Cereb Blood Flow Metab (1991) 11:716-25. doi:10.1038/jcbfm.1991.128

22. Yonas H, Gur D, Wolfson SK, Good WF, Good BC, Latchaw RE. Xenon-enhanced computerised tomographic cerebral blood flow mapping. Lancet (1984) 1:1357. doi:10.1016/S0140-6736(84)91856-7
23. Yonas H, Pindzola RP, Johnson DW. Xenon/computed tomography cerebral blood flow and its use in clinical management. Neurosurg Clin N Am (1996) 7:605-16.

24. Kety SS. The theory and applications of the exchange of inert gas at the lungs and tissues. Pharmacol Rev (1951) 3:1-41.

25. Hillered L, Vespa PM, Hovda DA. Translational neurochemical research in acute human brain injury: the current status and potential future for cerebral microdialysis. J Neurotrauma (2005) 22:3-41. doi:10.1089/neu.2005.22.3

26. Ungerstedt U, Rostami E. Microdialysis in neurointensive care. Curr Pharm Des (2004) 10:2145-52. doi:10.2174/1381612043384105

27. Ronne-Engstrom E, Cesarini KG, Enblad P, Hesselager G, Marklund N, Nilsson $\mathrm{P}$, et al. Intracerebral microdialysis in neurointensive care: the use of urea as an endogenous reference compound. J Neurosurg (2001) 94:397-402. doi:10.3171/jns.2001.94.3.0397

28. Carlson AP, Yonas H. Portable head computed tomography scanner - technology and applications: experience with 3421 scans. J Neuroimaging (2012) 22:408-15. doi:10.1111/j.1552-6569.2011.00621.x

29. Obrist WD, Langfitt TW, Jaggi JL, Cruz J, Gennarelli TA. Cerebral blood flow and metabolism in comatose patients with acute head injury. Relationship to intracranial hypertension. J Neurosurg. (1984) 61:241-53.

30. Kaufmann AM, Firlik AD, Fukui MB, Wechsler LR, Jungries CA, Yonas H. Ischemic core and penumbra in human stroke. Stroke (1999) 30:93-9. doi:10. 1161/01.STR.30.1.93

31. Yonas H, Gur D, Claassen D, Wolfson SK Jr, Moossy J. Stable xenon-enhanced CT measurement of cerebral blood flow in reversible focal ischemia in baboons. J Neurosurg (1990) 73:266-73. doi:10.3171/jns.1990.73.2.0266

32. Frijns CJ, Fijnheer R, Algra A, van Mourik JA, van Gijn J, Rinkel GJ. Early circulating levels of endothelial cell activation markers in aneurysmal subarachnoid haemorrhage: associations with cerebral ischaemic events and outcome. J Neurol Neurosurg Psychiatry (2006) 77:77-83. doi:10.1136/jnnp. 2005.064956

33. Ohkuma H, Manabe H, Tanaka M, Suzuki S. Impact of cerebral microcirculatory changes on cerebral blood flow during cerebral vasospasm after aneurysmal subarachnoid hemorrhage. Stroke (2000) 31:1621-7. doi:10.1161/01.STR.31.7. 1621

34. Suzuki S, Kimura M, Souma M, Ohkima H, Shimizu T, Iwabuchi T. Cerebral microthrombosis in symptomatic cerebral vasospasm - a quantitative histological study in autopsy cases. Neurol Med Chir (Tokyo). (1990) 30:309-16. doi:10.2176/nmc.30.309

35. Uhl E, Lehmberg J, Steiger HJ, Messmer K. Intraoperative detection of early microvasospasm in patients with subarachnoid hemorrhage by using orthogonal polarization spectral imaging. Neurosurgery (2003) 52:1307-15. doi:10. 1227/01.NEU.0000065154.04824.9E; disacussion 1315-1307,

36. De Micheli E, Pinna G, Piovan E, Prisco R, Hillered L, Persson L, et al. Monitoring subtle neurometabolic changes in subarachnoid hemorrhage patients using microdialysis: a study on 16 cases. Acta Neurochir Suppl (2001) 77: 149-53. doi:10.1007/978-3-7091-6232-3_32

37. Al-Rawi PG, Zygun D, Tseng MY, Hutchinson PJ, Matta BF, Kirkpatrick PJ. Cerebral blood flow augmentation in patients with severe subarachnoid haemorrhage. Acta NeurochirSuppl (2005) 95:123-7. doi:10.1007/3-211-32318-X_27

38. Enblad P, Frykholm P, Andersson J, Langstrom B, Hillered L, Persson L. PET scan in neuro-intensive care and research. Nord Med (1998) 113:49-52.

39. Enblad P, Valtysson J, Andersson J, Lilja A, Valind S, Antoni G, et al. Simultaneous intracerebral microdialysis and positron emission tomography in the detection of ischemia in patients with subarachnoid hemorrhage. J Cereb Blood Flow Metab (1996) 16:637-44. doi:10.1097/00004647-199607000-00014

40. Sarrafzadeh AS, Haux D, Ludemann L, Amthauer H, Plotkin M, Kuchler I, et al. Cerebral ischemia in aneurysmal subarachnoid hemorrhage: a correlative microdialysis-PET study. Stroke (2004) 35:638-43. doi:10.1161/01.STR. 0000116101.66624.F1

41. Nilsson OG, Brandt L, Ungerstedt U, Saveland H. Bedside detection of brain ischemia using intracerebral microdialysis: subarachnoid hemorrhage and delayed ischemic deterioration. Neurosurgery (1999) 45:1176-84; discussion 1184-1175. doi:10.1097/00006123-199911000-00032

42. Enblad P, Frykholm P, Valtysson J, Silander HC, Andersson J, Fasth KJ, et al. Middle cerebral artery occlusion and reperfusion in primates monitored by 
microdialysis and sequential positron emission tomography. Stroke (2001) 32:1574-80. doi:10.1161/01.STR.32.7.1574

43. Persson L, Valtysson J, Enblad P, Warme PE, Cesarini K, Lewen A, et al. Neurochemical monitoring using intracerebral microdialysis in patients with subarachnoid hemorrhage. J Neurosurg (1996) 84:606-16. doi:10.3171/jns.1996.84. 4.0606

Conflict of Interest Statement: The authors declare that the research was conducted in the absence of any commercial or financial relationships that could be construed as a potential conflict of interest.

Received: 01 April 2014; accepted: 20 May 2014; published online: 02 June 2014.
Citation: Rostami E, Engquist H, Johnson U, Howells T, Ronne-Engström E, Nilsson P, Hillered L, Lewén A and Enblad P (2014) Monitoring of cerebral blood flow and metabolism bedside in patients with subarachnoid hemorrhage - a Xenon-CT and microdialysis study. Front. Neurol. 5:89. doi: 10.3389/fneur.2014.00089

This article was submitted to Neurotrauma, a section of the journal Frontiers in Neurology.

Copyright $\odot 2014$ Rostami, Engquist, Johnson, Howells, Ronne-Engström, Nilsson, Hillered, Lewén and Enblad. This is an open-access article distributed under the terms of the Creative Commons Attribution License (CC BY). The use, distribution or reproduction in other forums is permitted, provided the original author(s) or licensor are credited and that the original publication in this journal is cited, in accordance with accepted academic practice. No use, distribution or reproduction is permitted which does not comply with these terms. 